Cahiers $d u$ MONDE RUSSE

\section{Cahiers du monde russe}

Russie - Empire russe - Union soviétique et États indépendants

$53 / 2-3 \mid 2012$

L'invention de la Sainte Russie

\title{
In memoriam Gilles Veinstein
}

\section{Olivier Bouquet}

\section{(2) OpenEdition \\ Journals}

Édition électronique

URL : http://journals.openedition.org/monderusse/9376

DOI : 10.4000/monderusse.9376

ISSN : $1777-5388$

Éditeur

Éditions de l'EHESS

Édition imprimée

Date de publication : 15 septembre 2012

Pagination : 283-287

ISSN : 1252-6576

\section{Référence électronique}

Olivier Bouquet, «In memoriam Gilles Veinstein », Cahiers du monde russe [En ligne], 53/2-3 | 2012, mis en ligne le 01 juillet 2015, Consulté le 30 avril 2019. URL : http://journals.openedition.org/

monderusse/9376 ; DOI : 10.4000/monderusse.9376 


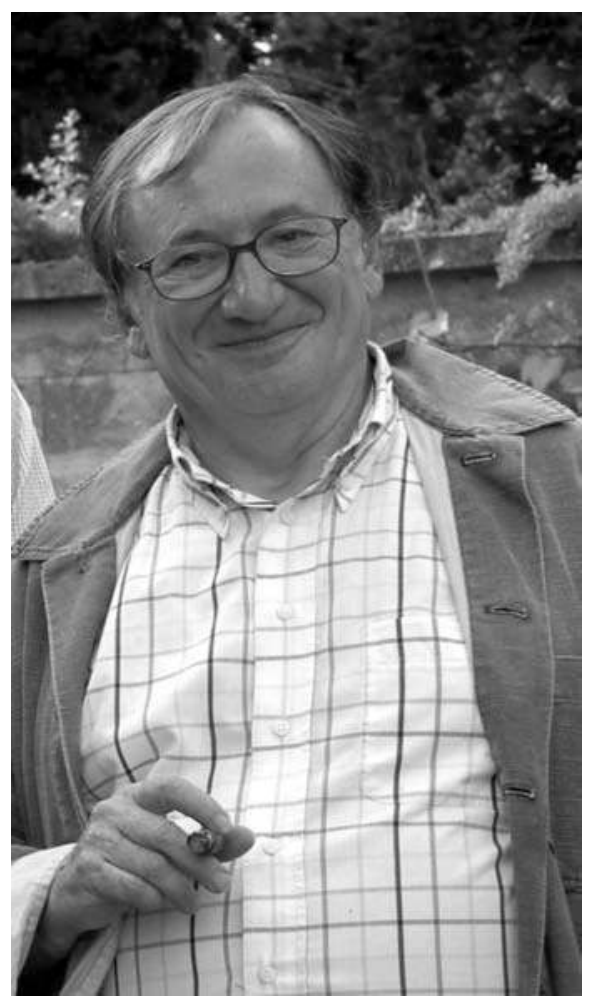

Gilles Veinstein (photographie N. Clayer) 


\section{IN MEMORIAM GILLES VEINSTEIN}

Gilles Veinstein nous a quittés au matin du 5 février, des suites d'une longue maladie. Depuis 1980, il était membre du comité de rédaction des Cahiers du Monde et russe et soviétique, devenus Cahiers du Monde russe. S'il était un éminent historien ottomaniste connu des spécialistes comme du grand public, avant tout pour ses œuvres sur les domaines du sultan, c'est par l'étude des territoires du nord-est de l'Empire avant la conquête russe qu'il avait débuté sa vie de chercheur. Dans les années 1970-1980, plusieurs de ses travaux contribuèrent à la connaissance des pays du Danube et de la mer Noire, à une époque où les dimensions islamiques et ottomanes des khanats échappaient en partie à l'historiographie russe et soviétique. C'est à ce titre qu'il fut estimé par ses collègues comme parfaitement qualifié pour prendre la tête, à l'EHESS, du centre d'études sur 1'URSS, l'Europe orientale et le domaine turc (1980-1995), dont il avait été directeur-adjoint à partir de 1976. Jusqu'à la fin de sa carrière et de sa vie, il ne cessa d'œuvrer aux rapprochements de l'étude des aires impériales russe et ottomane. C'est la raison pour laquelle la revue, dont il était un membre actif, souhaitait lui rendre un dernier hommage.

Né à Paris le 18 juillet 1945, Gilles Veinstein fut reçu à l'École normale supérieure en 1966 et à l'agrégation d'histoire en 1970. Dès la fin des années 1960, il s'était orienté vers l'étude de l'Orient islamique. Sa rencontre avec Alexandre Bennigsen, le spécialiste des musulmans soviétiques de la $\mathrm{VI}^{\mathrm{e}}$ section de l'EPHE, fut décisive. C'est lui qui attira l'attention du jeune étudiant sur le monde des Ottomans et qui l'encouragea, ainsi que Claude Cahen, à apprendre le turc à l'École des langues orientales sous la houlette de Louis Bazin. Dans la foulée, il fut initié à la paléographie ottomane au contact des meilleurs maîtres de l'époque : Pertev Boratav, Irène Beldiceanu Steinherr et Nicoara Beldiceanu. Chef de travaux, à la VI Section de l'EPHE entre 1972 et 1976, il gravit ensuite tous les échelons de l'EHESS (maître-assistant et maître de conférences (1977-1986), puis directeur d'études en 1986). Par ses publications, ses interventions dans des colloques internationaux, son enseignement qui attirait des disciples venus d'Europe et de Turquie, il ne tarda pas à s'affirmer comme un des meilleurs spécialistes du monde ottoman et, en France, comme le principal et le plus brillant moteur de ce domaine. Directeur de l'URA 1065 du CNRS (« Histoire de l'Empire ottoman, de l'Europe orientale et de la Turquie ») à partir de 1984, il opéra la fusion de celle-ci avec l'équipe d'études turques qu'avait créée Louis Bazin et que dirigeait 
alors James Hamilton : ainsi naquit l'URA 1425 «Études turques et ottomanes », toujours vivante aujourd'hui sous le nom de « Centre d'études turques, ottomanes, balkaniques et centre-asiatiques » (UMR 8032). Après son élection au Collège de France en décembre 1998 à la chaire d'Histoire turque et ottomane, vint le temps des grandes synthèses, marqué par la publication d'un essai sur les successions des sultans, d'un exposé magistral sur les relations de l'Empire ottoman avec l'Europe, et la parution régulière du résumé de ses cours, toujours savants, clairs et originaux. Son entrée au Collège traduisait la reconnaissance des études ottomanes comme discipline scientifique autant qu'elle soulignait le rôle de pionnier qu'il avait joué dans le désenclavement universitaire de la philologie turque. En ce sens, il était toujours resté fidèle à l'esprit d'Alexandre Bennigsen, disparu en 1988, et dont il avait coédité deux ouvrages collectifs sur les musulmans soviétiques.

Il faut rappeler le rôle que le maître avait joué sur son disciple lorsqu'il l'incita dès le début à consacrer ses travaux au nord de la mer Noire. En témoignent les deux premiers articles publiés par Gilles Veinstein en 1969 et 1970, qui portaient respectivement sur les missionnaires jésuites et agents français en Crimée au début du XVIII ${ }^{\mathrm{e}}$ siècle, et sur les Tatars de Crimée et la seconde élection de Stanislas Leszczynski. Par la suite, il avait élargi son étude des rapports russo-turcs et du khanat de Crimée à la question de l'émergence du problème cosaque : histoire du commerce, de la fiscalité, des sociétés. Épousant les intérêts d'Alexandre Bennigsen et de la remarquable équipe qui l'entourait, notamment Chantal Lemercier-Quelquejay, il fit dans l'ensemble de ses travaux un usage des archives impériales propre à déconcerter ceux qui l'avaient un peu vite étiqueté comme un historien de la Turquie : il s'en était notamment servi pour étudier des questions comme le peuplement et le commerce de la Crimée au $\mathrm{XvI}^{\mathrm{e}}$ siècle, le trafic moscovite des fourrures précieuses, de l'étain et des oiseaux de proie du Grand Nord. De la comptabilité ottomane, il avait tiré de précieuses informations sur la pêche à l'esturgeon et la collecte du caviar dans la mer d'Azov qui avait attiré l'attention de plusieurs hydrologues soviétiques. La mise en place des institutions ottomanes dans les pays occupés et la persistance de législations locales antérieures suscitaient particulièrement son intérêt. Son étude des registres de recensement et de la correspondance de Soliman le Magnifique avec les rois de Pologne lui permit d'offrir des éléments d'interprétation nouveaux sur les cosaques zaporogues qui suscitèrent d'importants débats chez d'éminents ukrainologues. Gilles Veinstein avait en effet montré que les premiers raids ne devaient pas être seulement interprétés comme une riposte populaire spontanée aux incursions tatares : ils étaient en fait commandités par les nobles polono-lithuaniens, gouverneurs des forteresses du limes, les Pretwicz, les Sieniawski, ou les Sanguszko. Ces derniers s'étaient opposés à l'avance ottomane dans la région, champions politiques des droits historiques de l'État lithuanien, également désireux de développer leurs intérêts économiques.

De même, alors que plusieurs historiens de la mer Noire avaient vu dans l'arrivée des Turcs le point final d'une longue tradition d'échanges, GillesVeinstein s'était dit frappé par la continuité des courants commerciaux déjà mis en place dans les derniers temps des colonies vénitiennes et génoises. Il l'avait notamment constaté 
dans le cas du commerce entre l'Empire ottoman et la Moscovie, via la Pologne, dans lequel les textiles anatoliens, l'argent et les épices s'échangeaient contre l'étain, les gerfauts, les dents de morse et surtout les fourrures du Grand Nord, article essentiel de l'étiquette impériale stambouliote. Les agents de ce commerce, facteur essentiel de la politique régionale, comprenaient, du côté ottoman, des marchands de la Cour et des particuliers, chrétiens, juifs, mais aussi musulmans. Ces derniers, loin de dédaigner de s'adonner au négoce, montrait Gilles Veinstein, ne craignaient pas de s'aventurer jusqu'en terre infidèle.

Si dans les premiers temps, notamment lors d'un colloque d'historiens franco-soviétiques tenu à Moscou en 1978, les résultats de ses recherches semblaient passer inaperçus, ils rencontrèrent ultérieurement une attention soutenue et une compréhension particulière de la part de l'Institut d'études ukrainiennes de Harvard. Son directeur, Omeljan Pritsak, l'avait invité à deux reprises, en 1981 et en 1986, à soumettre ses travaux à de fructueuses discussions dont avait résulté une collaboration suivie qui s'élargit ensuite à l'Institut d'études orientales de Kiev. Il est vrai qu'à cette époque, conjointement à ses travaux sur les relations des sultans avec le monde russe, Gilles Veinstein se tournait davantage vers des questions foncières et fiscales dont il établissait l'importance pour l'économie et les sociétés ottomanes en Anatolie ou dans les Balkans. Mais le spécialiste du monde musulman qu'il était devenu au fil des ans, loin de l'éloigner de l'intérêt qu'il portait aux domaines territoriaux des steppes et des confins, ne cessait d'approfondir - sa bibliographie des vingt dernières années en témoigne - l'étude des sociétés qui y vivaient et des pouvoirs qui s'y imposaient. Si Gilles Veinstein était devenu le meilleur des ottomanistes, il garda toujours un goût singulier pour les Turcica-Russica et fut sensible aux progrès et aux évolutions conjointes des historiographies impériales de la période moderne.

Olivier Bouquet

CETOBAC, EHESS, Paris 